\title{
Antonio Jacinto e o poema “Carta de um contratado": diálogo no espaço da língua portuguesa
}

Sérgio Paulo Adolfo

Universidade Estadual de Londrina

RESUMO: O ARTIGO ANALISARÁ O POEMA "CARTA DE UM CONTRATADO" DO POETA ANGOLANO ANTONIO JACINTO, OBSERVANDO A PARTIR DELE O PAPEL DO INTELECTUAL AFRICANO DURANTE O REGIME COLONIAL; A IMPOSSIBILIDADE DE DOMINAR OS CÓDIGOS DA ESCRITA COMO MARCA DE INTERDIÇÃO DO SUJEITO COLONIZADO. AO MESMO TEMPO, SE DISCUTIRÁ EM QUE MEDIDA A ESCRITA É VALORIZADA NO POEMA COMO SOLUÇÃO IMEDIATA PARA A SUPERAÇÃO DAS DESIGUALDADES PERPETUADAS PELO REGIME OPRESSOR, INCLUSIVE EM DETRIMENTO DE VALORES TRADICIONAIS.

ABSTRACT: THIS PAPER AIMS TO ANALYZE THE POEM "CARTA DE UM CONTRATADO", BY THE ANGOLAN POET ANTONIO JACINTO. WE INTENDS TO OBSERVE IN IT THE ROLE OF THE AFRICAN INTELLECTUALS DURING THE COLONIAL REGIME; THE INABILITY TO MASTER THE CODES OF WRITING AS A MARK OF INTERDICTION OF THE COLONIZED SUBJECT. AT THE SAME TIME, IT WILL DISCUSS THE EXTENT TO WHICH THE WRITING IS VALUED IN THE POEM AS AN IMMEDIATE SOLUTION TO OVERCOME THE INEQUALITIES PERPETUATED BY THE OPPRESSIVE REGIME, EVEN AT THE EXPENSE OF TRADITIONAL VALUES.

PALAVRAS-CHAVE: POESIA ANGOLANA, ANTONIO JACINTO, "CARTA DE UM CONTRATADO", INTELECTUALIDADE, COLONIALISMO.

KEYWORDS: ANGOLAN POETRY, ANTONIO JACINTO, "CARTA DE UM CONTRATADO", INTELLECTUALITY, COLONIALISM. 


\section{ntrodução}

António Jacinto, poeta angolano pertencente à geração do movimento intelectual Vamos descobrir Angola e da Revista Mensagem, denuncia em seu poema "Carta de um contratado" as vicissitudes da realidade colonial portuguesa, no que respeita à questão da alfabetização, incisivamente negada à população autóctone, aos povos tradicionais, aos filhos da terra. Nesse poema-narrativo, o eu lírico é impossibilitado de realizar o seu intento amoroso, pois tanto ele quanto a sua amada não estão intrumentalizados com os códigos da escrita e, portanto, são incapazes de escrever ou ler uma carta, que seria capaz de amenizar a saudade provocada pela distância entre a plantação onde fora enviado como trabalhador "contratado" e o seu local de origem, onde permaneceu a mulher amada.

Na construção do poema, cuja temática é essa incomunicabilidade pela língua escrita, encontramos, logo na primeira estrofe, referência ao maior poeta épico de língua portuguesa, Camões, em alguns de seus mais expressivos versos líricos, em que se define magistralmente o sentimento amoroso. $\mathrm{Na}$ segunda estrofe do poema de Jacinto, ao descrever a mulher amada, o eu lírico dialoga, desta vez, com a literatura romântica brasileira, com o romancista José de Alencar e o seu célebre Iracema.

Esse diálogo intertextual no espaço de um poema, cuja temática é a ausência da escritura como possibilidade afetiva, faz emergir, ao mesmo tempo, o estilo criativo de António Jacinto, indicando o seu lugar no mundo literário de língua portuguesa e a sua crítica ao sistema colonial português então vigente. Acresce-se a isso as perplexidades do intelectual colonizado que se vê no dilema de pertencer a um só mundo de aspectos contraditórios: o mundo do qual ele faz parte como elite intelectual dominante, mas um mundo do qual a extensa maioria de seus conterrâneos foi alijada.

\section{Colonialismo e Intelectualidade}

Frantz Fanon aborda o colonialismo sob dois aspectos: destaca a "doença colonialista" e o "colonizado doentio". Os valores coloniais distorcem a condição humana, tornando o homem colonizado - nativo ou não - um fantoche, 
um arremedo daquele que se julga ser o modelo ideal. Para além das consciências, o colonialismo age subvertendo a ordem cultural; destruindo a possibilidade das dinâmicas e lógicas culturais próprias de cada povo; fazendo com que invertam os valores mais íntimos de sua própria cultura em prol da valorização da cultura do outro, do colonizador. A força bruta aliada à ideologia veiculada pela retórica induz muitas vezes as massas nativas a abandonarem suas tradições e valores, renegarem o seu modo de ser e fazer. A população nativa elege valores estranhos à sua história e seu passado; um passado que finda por ser olvidado e até mitificado em favor da própria ideologia colonial.

Os movimentos de independência, ao se colocarem em ação para libertar seus povos do jugo colonial, prometem uma felicidade utópica, uma simples troca de lugares, como se somente a saída do colonizador fosse suficiente para garantir moradia, condições de saúde, educação, enfim, o bem estar que o cidadão nativo se acostumou a ver e pressentir, se colocando em comparação com a situação do colonizador. Neste cenário, algumas vezes se inverte o racismo apregoado pelo colonizador, e os nativos passam a ver na figura do branco o exclusivo símbolo da opressão, da miséria, do domínio colonial, como se a cor fosse o apanágio da dominação. Em parêntese: mesmo após a independência das colônias, o mundo invertido que o colonialista criou, irá, na verdade, continuar invertido; porém agora a inversão se dará entre a elite nacional e o povo. Essa elite nacional composta dos filhos da terra, com formação nas metrópoles e, não raro, por elas cooptada como agentes mantenedores de privilégios.

Retomando as questões inerentes ao espaço colonizado podemos questionar: de que lado se posiciona o intelectual do país de Angola? O colonizado, como bem alerta Frantz Fanon, é um homem de dois mundos, mas de dois mundos que não se harmonizam, de dois universos que se confrontam. $\mathrm{Na}$ ótica colonial a sobrevivência do mundo tradicional se constitui numa perigosa ameaça à sua própria sobrevivência. A permanência dos valores tradicionais, da história nacional e de suas línguas colocaria em risco o prestígio das metrópoles e seu domínio sócio político. O intelectual colonizado tem ciência da corrosão social praticada contra o seu povo e, no entanto, às vezes não tem a justa opção de escolha, dado o nível de imersão na cultura do outro. Os valores ocidentais se apresentam de tal forma privilegiados e sedutores aos seus olhos, que ele passa a acreditar que a única saída para o seu povo é o caminho oferecido pelo modo de ser das metrópoles. 
Neste espaço de contradições e inseguranças situamos Antonio Jacinto, nome poético de António Jacinto do Amaral Martins, nascido no Golungo Alto, em 28 de Setembro de 1924. Jacinto concluiu seus estudos licenciais em Luanda, passando a trabalhar como funcionário de escritório. Destacou-se como poeta e contista da geração Mensagem e, em consequência de seus envolvimentos políticos, foi preso no campo de concentração do Tarrafal, Cabo Verde, onde cumpriu pena de 1960 a 1972. Neste mesmo ano foi transferido para Lisboa, em regime de liberdade condicional, onde exerceu a função de técnico em contabilidade. Fugiu da capital portuguesa em 1973 e foi integrar a luta pela independência de Angola, participando das frentes militantes do MPLA. Após a independência, foi Ministro da Cultura de 1975 a 1978. Morreu em 23 de Junho de 1991.

Em sua carreira de escritor, Jacinto colaborou com produções em diversos periódicos: Jornal de Angola, Notícias do Bloqueio, Itinerário, Império e Brado Africano e foi membro da revista Mensagem. De sua escrita poética nos chegaram os livros Poemas (1961); Outra vez. Vovô Bartolomen (1979), Sobreviver em Tarrafal de Santiago (1985).

Seu poema, "Carta de um contratado" dá bem a medida da angústia do homem entre dois mundos, conforme vimos discutindo acima. A seguir, transcreveremos o poema, integralmente, para melhor compreensão do que queremos expor.

\section{"Carta de um Contratado"}

Eu queria escrever-te uma carta

amor

uma carta que dissesse

deste anseio

de te ver

deste receio de te perder

deste mais que bem querer que sinto

deste mal indefinido que me persegue

desta saudade a que vivo todo entregue...

Eu queria escrever-te uma carta

amor 
uma carta de confidências íntimas

uma carta de lembranças de ti

de ti

dos teus lábios vermelhos como tacula

dos teus cabelos negros como dilôa

dos teus olhos doces como macongue

dos teus seios duros como maboque

do teu andar de onça

e dos teus carinhos

que maiores não encontrei por aí...

Eu queria escrever-te uma carta

amor

que recordasse nossos dias na capôpa

nossas noites perdidas no capim

que recordasse a sombra que nos caía dos jambos

o luar que se coava das palmeiras sem fim

que recordasse a loucura

da nossa paixão

e a amargura nossa separação...

Eu queria escrever-te uma carta

amor

que a não lesses sem suspirar

que a escondesses de papai Bombo

que a sonegasses a mamãe Kieza

que a relesses sem a frieza

do esquecimento

uma carta que em todo Kilombo

outra a ela não tivesse merecimento...

Eu queria escrever-te uma carta

amor

uma carta que te levasse o vento que passa

uma carta que os cajus e cafeeiros 
que as hienas e palancas

que os jacarés e bagres

pudessem entender

para que se o vento a perdesse no caminho

os bichos e plantas

compadecidos de nosso pungente sofrer

de canto em canto

de lamento em lamento

de farfalhar em farfalhar

te levasse puras e quentes

as palavras ardentes

as palavras magoadas da minha carta

que eu queria escrever-te amor...

Eu queria escrever-te uma carta...

Mas ah meu amor, eu não sei compreender

por que é, por que é, por que é, meu bem

que tu não sabes ler

e eu - Oh! Desespero - não sei escrever também!

Antonio Jacinto (Poemas, 1961)

\section{Mundo tradicional versus mundo colonizado}

Os ambundos que compunham o outrora reino de Ngola, nome que dá origem ao hoje moderno país de Angola, é um povo de língua kimbundo; ocupa grande parte do país, desde o oceano atlântico, no norte de Angola, em direção ao interior, até o rio Cuango. São tradicionalmente agricultores e seu principal cultivo é o da mandioca, e por extensão, sua principal fonte de alimentos. Foram pioneiros no plantio do arroz e produzem café de boa qualidade para exportação. Talvez seja o grupo angolano mais assimilado à cultura europeia, e foi o primeiro a ter a escrita em sua língua, o kimbundo.

Eles foram contatados oficialmente pelos portugueses, através de um navegador chamado Paulo de Novais, em 1565. Nessa época o rei local era Ndembi a Ngola, que mandou ao rei português, por Paulo de Novais, 40 argolas de 
cobre, 40 peças de pau aromático, 35 presas de elefante e alguns escravos. Não recebeu nenhuma notícia de Paulo Novais, nem dos presentes enviados ao monarca português, durante dez longos anos. Quando Paulo Novais voltou, em 1575 já era outro o rei governante, e desta vez Paulo Novais trazia em sua companhia 700 soldados, marinheiros e artífices, além de padres jesuítas acomodados em sete ou nove navios. Foi a cobiça que motivou Paulo de Novais a voltar à Angola, pois acreditava que o país fosse rico em jazidas de prata, cobre e sal e que, através de Angola, poder-se-ia alcançar o fabuloso reino de Monomotapa no outro lado do continente, onde hoje é Moçambique. Paulo de Novais fundeou seus navios na ilha de Luanda, na época pertencente ao rei do Congo, de onde o mesmo extraia cauris que usava como moeda corrente no seu reino.

Apesar das cautelas do rei de Ngola, os portugueses saltaram da ilha de Luanda para terra firme, onde começaram a construir capelas, casas, feitorias e tudo quanto fosse necessário para se estabelecerem e iniciar um lucrativo negócio de venda de escravos. Tiveram como parceiro no negócio o próprio rei de Ngola, que já praticava esse comércio há tempos com outros portugueses e europeus de várias procedências.

Dos primeiros contatos dos portugueses em terras da futura Angola até o estatuto da colonização foram alguns séculos, durante os quais os colonizadores foram aos poucos e de forma violenta se apossando dos bens culturais e das riquezas materiais do país invadido. Várias obras literárias contemporâneas retratam esse processo; por exemplo, algumas de Pepetela, como os romances Yaka e A Gloriosa Família que recontam de forma ficcional o lento e inexorável processo histórico da dominação portuguesa em terras angolanas.

Séculos depois, o grupo condutor da independência de Angola, o MPLA, formou-se a partir do grupo Kimbundo (dos ambundos), pois a maior parte de seus membros pertencia a essa etnia. Com o MPLA vitorioso nas lutas pela independência do país, o kimbundo passou a ser a língua mais prestigiada na nova nação, e não por acaso grande parte dos escritores da moderna literatura angolana tem usado o kimbundo como parte das suas criações literárias.

Ao longo do processo de independência, o controle de Angola estava dividido pelos três maiores grupos nacionalistas o MPLA, a UNITA e o FNLA, pelo que a independência foi proclamada unilateralmente pelos três movimentos. $\mathrm{O}$ MPLA que controlava a capital, Luanda, proclamou a Independência da Repú-

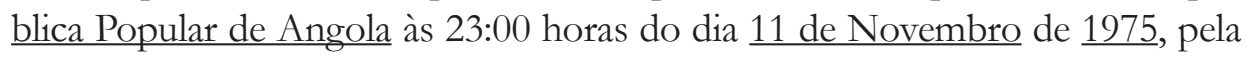


voz de Agostinho Neto dizendo, "diante de África e do mundo proclamo a Independência de Angola", culminando assim o périplo independentista, iniciado no dia 4 de

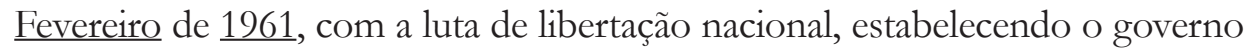
em Luanda com a Presidência entregue ao líder do movimento.

Ao mesmo tempo, Holden Roberto, líder da FNLA, proclamava a Independência da República Popular e Democrática de Angola à meia-noite do dia 11 de Novembro, no Ambriz. E ainda nesse mesmo dia, a independência foi também proclamada em Nova Lisboa (uambo), por Jonas Savimbi, líder da UNITA.

No dia anterior, 10 de Novembro de 1975, o Alto Comissário e Governador-Geral de Angola, almirante Leonel Cardoso, em nome do Governo Português, proclamara a independência de Angola, transferindo a soberania de Portugal, não para um determinado movimento político mas sim para o "Povo Angolano", de forma efectiva a partir de 11 de Novembro de 1975. ("E assim Portugal entrega Angola aos angolanos, depois de quase 500 anos de presença, durante os quais se foram cimentando amizades e caldeando culturas, com ingredientes que nada poderá destruir. Os homens desaparecem, mas a obra fica. Portugal parte sem sentimentos de culpa e sem ter de que se envergonhar. Deixa um país que está na vanguarda dos estados africanos, deixa um país de que se orgulha e de que todos os angolanos podem orgulhar-se").

A fala do almirante Leonel Cardoso explicita a lógica da dominação colonial " depois de quase 500 anos de presença, durante os quais se foram cimentando amizades e caldeando culturas" e é exatamente a partir dessa fala, que representa o pensamento da colonização que queremos tecer alguns breves comentários, tendo como base o poema de Antonio Jacinto.

A grande questão apresentada pelo eu poético em "Carta de um contratado" é exatamente a ausência da educação formal para as populações africanas na colônia portuguesa. Nele, o mal de amor sofrido pelos sujeitos do poema é alimentado justamente pela impossibilidade de comunicação, pois sendo analfabetos não podem enviar notícias de si pela escrita e leitura, de tal modo que a separação se torna ainda mais dolorosa.

Eu queria escrever-te uma carta...

Mas ah meu amor, eu não sei compreender

por que é, por que é, por que é, meu bem

que tu não sabes ler

e eu - Oh! Desespero - não sei escrever também! 
A impossibilidade da escrita e da leitura impede o reencontro "virtual" dos amantes, e é essa a tônica da lamentação do poema, cujo tema é um amor impedido pela distância, visto que o amante está cumprindo o "contrato" longe da sua terra e da mulher amada. Tendo como pano de fundo o mundo colonial, em que a cultura letrada era valorizada, mas sem acessibilidade a todos, o poema desmente o "caldeamento de culturas", nas palavras do almirante português, e denuncia a cisão prevalecente durante os séculos de ocupação, entre o mundo tradicional africano e o "mundo do colonizador" no espaço africano.

No poema, o contratado, arrancado do seu ambiente familiar para um ambiente hostil, longe da mulher amada e de quem não tem notícias, nem mesmo por meio do benefício mínimo prometido na ideia de "civilização", a escrita.

amor

que recordasse nossos dias na capôpa

nossas noites perdidas no capim

que recordasse a sombra que nos caía dos jambos

o luar que se coava das palmeiras sem fim

que recordasse a loucura

da nossa paixão

e a amargura da nossa separação...

A separação como tema remete à ideologia da colonização e da exploração, pois, se no passado a empresa europeia explorou economicamente a escravidão, separando indivíduos da terra africana, continuava agora a fazê-lo pela instituição do contrato. E nem mesmo um meio de comunicação simples e eficiente, a escrita, estava à disposição dos colonizados do século XX. Sem os tradicionais tambores, meio de comunicação ancestral, caberia à carta o papel de levar as palavras pelas ondas do vento:

amor

uma carta que te levasse o vento que passa

uma carta que os cajus e cafeeiros

que as hienas e palancas

que os jacarés e bagres

pudessem entender 
para que se o vento a perdesse no caminho

os bichos e plantas

compadecidos de nosso pungente sofrer

de canto em canto

de lamento em lamento

de farfalhar em farfalhar

te levasse puras e quentes

as palavras ardentes

as palavras magoadas da minha carta

que eu queria escrever-te amor...

A natureza, cuja relação com o homem do mundo tradicional é simbiótica, está presente no poema como mensageira do apaixonado ("uma carta que te levasse o vento que passa"). Mas os tempos são outros, e os mecanismos de interação entre seres e pessoas passaram a ser, também, a tecnologia do outro, do colonizador. Neste caso, a tecnologia da escrita, sempre apresentada como superior e melhor, mas negada ao indivíduo autóctone.

Nessas estrofes, em que o eu poético lamenta não poder utilizar-se da natureza, está revelada a perplexidade do homem colonizado perante os efeitos negativos da colonização; as mudanças de postura e de mentalidade que os nativos são obrigados a adotar, em detrimento de um mundo, cuja vivência seria facilitada pelas suas próprias formas culturais. Os versos parecem ensejar uma positiva relação dialética, em que a cosmovisão tradicional e aquela trazida pelo colonizador pudessem encontrar um lugar comum, no qual a exploração física e a submissão cultural estivessem ausentes.

De fato, o poema em si é uma prova acabada da mestiçagem cultural e do encontro de culturas tão díspares. Percebe-se através da escritura que o poeta Antonio Jacinto é um homem do mundo português, pois o seu poema contém releituras de autores portugueses e brasileiros. Percebe-se na primeira estrofe, uma forte influência de Camões:

Eu queria escrever-te uma carta

amor

uma carta que dissesse

deste anseio 
de te ver

deste receio de te perder

deste mais que bem querer que sinto

deste mal indefinido que me persegue

desta saudade a que vivo todo entregue...

Ao definir o sentimento amoroso, Antonio Jacinto conduz o leitor lusófono para as páginas do soneto camoniano, na sua definição clássica de amor. $\mathrm{E}$ na segunda estrofe, o autor recorre a José de Alencar, também no seu clássico Iracema ao fazer comparações da heroína com alguns animais e frutos da região tal como fez aquele autor.

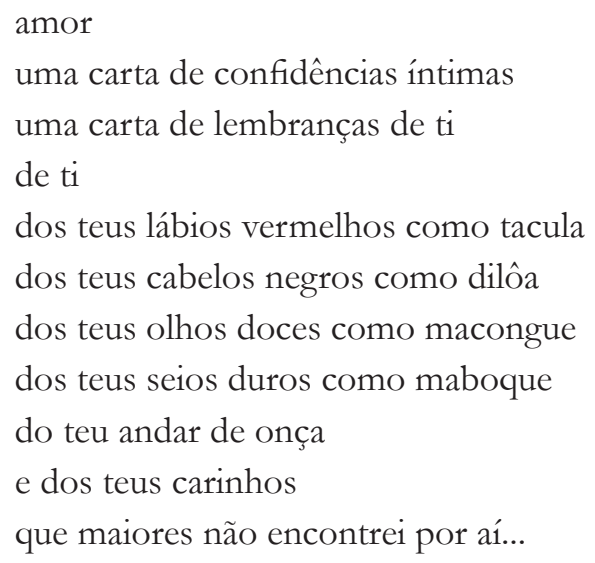

Iniciamos nossa reflexão abordando a questão do homem colonizado como homem de dois mundos. O mundo colonizado e a metrópole, sendo que a segunda impõe sua autoridade utilizando-se da força, mas também da ideologia. Para que o dominado aceite a dominação é necessário que o dominador lance mão dos acessórios de que dispõe em detrimento do arcabouço cultural do outro. Para tal, é desvalorizada a cultura do outro, sua "raça", religião e crença, valorizando sobremaneira as qualidades do dominante. Isso coloca em evidência o que se defende como fator de civilização, fazendo que o outro passe a considerar as suas crenças e valores "bárbaros", e o colonizador como detentor de uma "raça", de uma cultura e de uma religiosidade superiores. O nativo passará então a acreditar no outro e desacreditar de si 
mesmo, buscando ilusoriamente assemelhar-se ao outro, para sentir-se igualmente superior, civilizado e apto a assumir o papel do outro.

O poema apresenta-se sob alguns outros ângulos. Sob o ponto de vista do eu poético, toda a sua infelicidade centra-se no fato de não dispor de um arcabouço de leitura e escrita, assim como acontece com a mulher amada. Fossem eles detentores desses bens, o sofrimento amoroso seria minimizado, pois poderiam comunicar-se. Os mecanismos tradicionais de comunicação já não atendem plenamente os novos tempos. O novo meio de comunicação, escrito, trazido pelo europeu não está ao alcance de todos; portanto, também não serve aos amantes.

Esse indivíduo, duplamente oprimido, pelo contrato e pelo analfabetismo, não percebe conscientemente a dimensão das injustiças a que está submetido pela ordem colonial. Ele apenas sofre, sem conseguir entender porque tais coisas acontecem.

Por outro ângulo, podemos analisar o papel do poeta, do homem escritor, do intelectual engajado na luta pela libertação. E aqui retomamos a questão sobre como se posiciona esse intelectual perante a realidade colonial. Há uma oposição no seu poema, entre o tradicional e o moderno, entre os hábitos da terra e a herança colonial que não deixa dúvidas sobre a posição do poeta. Simbolicamente, a carência de alfabetização, do saber dominar as técnicas trazidas pelo colonizador e pela civilização é um entrave à realização amorosa dos amantes africanos, que se veem impedidos da concretização afetiva. Assim, enquanto denuncia o descaso da metrópole em relação à vida dos colonizados, o poeta também aponta o aprendizado da leitura e da escrita como uma solução imediata.

Nessa chave interpretativa, pode-se conjeturar também que para esse intelectual colonizado não existiria outra saída para o povo angolano senão a aderência completa ao modo de ser metropolitano. O colonizado deve assimilar a cultura ocidental e seus valores em detrimento dos seus próprios. Quando Fanon analisa o papel do intelectual colonizado e assimilado à cultura do outro, ele está justamente tratando do mal estar causado pela atitude de valorização da cultura do outro em detrimento da sua de origem.

Os colonizadores conseguiram implantar em mentes e corações colonizados os seus próprios valores, de forma que esses indivíduos, passassem a menosprezar a sua própria cultura. A ideologia do dominador é construída 
e retroalimentada de maneira a parecer necessária e indispensável ao colonizado; este, por sua vez, se torna um devedor pela dominação. Os valores tradicionais não são mais levados em conta, principalmente pelos africanos assimilados, grupo a que pertence a maior parte dos intelectuais. Comparados aos valores trazidos de fora, os valores da terra passam a ser vistos como folclóricos quando não exóticos e bizarros. Muitos filhos da terra, ofuscados pelos lumes da nova civilização, deixam de questionar se todos os valores trazidos e impostos pelo colonizador são a medida do seu povo.

\section{Ecos da Negritude em Antonio Jacinto}

"Negritude" é termo que foi cunhado pela primeira vez por Aimé Césaire, em 1938, em seu livro de poemas, "Cahier d'un retour au pays natal', e que tem como principais responsáveis e dinamizadores Léopold Sédar Senghor (1906) senegalês; Aimé Césaire (1913), martinicano; e Leon Damas (1912), ganês. Já o sentido de "negritude" vem carregado de ambiguidade. Os autores da Negritude legaram-nos uma obra literária da máxima importância, mas foi Senghor que, com a Presidência do seu país (Senegal) e como escritor de larga aceitação ocidental (política literária e acadêmica) contribuiu decisivamente para a divulgação da Negritude.

É a Senghor que são atribuídas as primeiras tentativas de definição do conceito de Negritude: "Conjunto dos valores culturais do mundo negro".

Eis alguns valores característicos do homem negro:

- O homem negro é essencialmente religioso e cultural, ritual e celebrante, porque para ele existe um ente supremo, o "sagrado", que é o verdadeiro real;

- O homem negro é simbólico, porque o seu mundo é o mundo das imagens e do concreto; todas as realidades materiais, visíveis e imediatas são anunciadoras e portadoras de outras realidades;

- O homem negro é o homem de coração, porque, para além do corpo, da forca vital, da habilidade, do entendimento e de todas as outras qualidades humanas, é ainda pelo coração que o homem se define, que o homem vale e é julgado; para usar a categoria de um provérbio africano: "o coração do bomem é o seu rei". 
Como podemos perceber, Senghor ao definir o homem negro, busca diferenciá-lo do ocidental pelas suas qualidades emotivas, como se à raça negra apenas coubesse o papel da arte e não da tecnologia. A negritude como movimento estético-político muito contribuiu para uma melhor compreensão do homem negro e seus mundos, mas ao mesmo tempo limita o homem negro a determinadas capacidades distantes do ideário colonial, da ideia de progresso material e técnico.

Senghor, como outros intelectuais colonizados, acaba por assimilar o pensamento ocidental sobre o homem negro, pensamento esse criado e usado pelos ocidentais para melhor dominar e colonizar os povos não europeus.

Os intelectuais de um país colonizado pertencem à elite desse país, se não a elite econômica, pelo menos à elite cultural, porque foram os que tiveram oportunidade de estudar nas escolas metropolitanas da colônia ou da própria metrópole e, certamente, são os mais suscetíveis de serem transformados pelo pensamento metropolitano. A sedução exercida pela metrópole sobre esses jovens é muito forte, não raras vezes, transformando-os em meros fantoches da cultura do outro. Quando saem dessa imersão no mundo da metrópole, são pessoas profundamente apegadas aos valores ocidentais, cheios de ideias de libertação, mas uma libertação que os livrará das peias da metrópole sem, no entanto, livrá-los das amarras da ideologia do colonizador.

No poema de Antonio Jacinto, percebe-se claramente esta ambiguidade do intelectual colonizado perante sua própria cultura. O caminho apontado pelo poeta é o da escolarização nos moldes europeus, pois a cultura tradicional africana sozinha já não funcionaria na resolução dos problemas do homem angolano. A única solução apontada no poema é a escolarização, veículo importante da dominação colonial, pois é através da escola, que geralmente as metrópoles cooptam os jovens a seu favor, dado o fascínio e as oportunidades que a escolaridade oferece. Ser assimilado numa sociedade colonial tem como ponto de partida o saber ler e escrever na língua do usurpador.

Como última análise podemos também ver o poema como a relação do colonizado e seu país, como uma história de amor mal resolvida, entre o homem colonizado e sua terra conquistada. A terra querida e desejada longe do homem angolano, porque em mãos de um poder que não lhe pertence. A mulher ali representada possui todos os componentes da pátria africana personificada: é sensual, lânguida, bela, desejada. Mas está distante daquele que a 
ama, pois que está tangido pelo contrato — também um "contrato colonial"? Longe de sua pátria, metafórica ou real, ela torna-se inatingível pela impossibilidade da escrita. O eu poético traz em sua voz a presença de dois mundos, o mundo ocidental através de Camões e José de Alencar, e o mundo africano, representado pela sua natureza (animais, plantas, flores e frutos).

De modo interessante, ao usar os estereótipos do colonizador a respeito da terra africana, principalmente o famigerado exotismo, o homem-poeta ressalta a diferença entre eles (colonizadores) e nós (colonizados). Essa aparência de exótico serve, na verdade, para sobrelevar as marcas do amor à africanidade renegada pelo colonizador, mas ainda plena de significados pelo homem da terra.

que recordasse nossos dias na capôpa

nossas noites perdidas no capim

que recordasse a sombra que nos caía dos jambos

o luar que se coava das palmeiras sem fim

que recordasse a loucura

da nossa paixão

\section{Conclusão}

Os séculos de civilização africana foram colocados em xeque pela ação portuguesa, sendo agredida e suplantada pela ação colonial. Esse novo mundo formado de valores ocidentais e africanos prioriza, entretanto, a cultura ocidental em detrimento da cultura africana; e é neste espaço onde os intelectuais vivem e produzem, embora sejam formados na escola do Ocidente. Esses intelectuais, não raro, eram tomados de uma grande angústia, diante do dilema de escrever para o seu povo sobre o drama do colonialismo, mas fazêlo na língua e normas do colonizador europeu. Antonio Jacinto foi também o poeta dessa contradição e ambiguidade. Em suas produções estão manifestas a dor e a angústia de uma realidade insustentável sob o poder colonial. Constatamos isso com maior agudeza em "Poema da alienação", momento em que o eu lírico se confessa como um poema em construção, cujo verdadeiro poema é seu povo, mas do qual ele ainda não faz parte, por isso se posiciona como um poema ainda em construção. 


\section{"Poema da Alienação"}

Não é este ainda o meu poema

o poema da minha alma e do meu sangue

กão

Eu ainda não sei nem posso escrever o meu poema

o grande poema que sinto já circular em mim

$(\ldots)$

o meu poema sou eu-branco

montado em mim-preto

a cavalgar pela vida.

(Antonio Jacinto, 1961)

\section{Referência Bibliográfica}

ABRANCHES, Henrique. Reflexões sobre cultura Angolana. África, I, ano I, Lisboa: 1978. ALENCAR, José de. Iracema. São Paulo, Ática, 1982.

CAMÕES, Luís de. Os Lusíadas. São Paulo: Klick editora, 2.000.

CANDIDO, Antônio. Literatura e Sociedade. São Paulo: Nacional, 1972. A literatura e a formação do homem. Texto policopiado.

FANON, Frantz. Los Condenados de la tierra. México: Ponto de Cultura Econômica, 1977.

JACINTO, Antonio. Poemas, Casa dos Estudantes do Império. Lisboa: 1961

MEMMI, Albert. O retrato do colonizado precedido do retrato do colonizador. Rio de Janeiro: Paz e Terra, 1977.

MOURÃO, F. Augusto Albuquerque. A sociedade angolana através da literatura. São Paulo: Ática, 1978.

MUNANGA, Kabenguele. Negritude, usos e costumes. São Paulo: Ática, 1986.

Silva, Alberto da Costa e. A manilha e o libambo. Rio de Janeiro:Nova Fronteira, 2002. 